\section{Results}

Fourteen CSF specimens, four paired and six at acute phase, from 10 infants with benign convulsions associated with rotavirus gastroenteritis yielded negative results. Eight (17 CSF specimens) of 173 patients (230 CSF specimens) with other neurological diseases yielded positive results. These positive specimens were pretreated with rotavirus and showed more than $50 \%$ blocking.

Twelve specimens were positive in specific IgG, eight in specific IgM, and seven in specific $\operatorname{IgA}$. The positive cases comprised one newborn infant with Escherichia coli meningitis simultaneously afflicted with rotavirus gastroenteritis, one infant with group B streptococcus meningitis who later had rotavirus gastroenteritis, one child with mumps meningitis, one child with Japanese encephalitis, three adults with brain tumour who received chemotherapy and radiation treatment, one adult with neuro-Behcet's syndrome, and one child with congenital brain anomaly and hydrocephalus with shunt treatment.

\section{Discussion}

Rotavirus is an important cause of acute gastroenteritis in children. Patients with convulsions, encephalopathy, and (suspected) encephalitis have occasionally had rotavirus gastroenteritis. ${ }^{134}$ Antirotavirus antibodies were found in CSF specimens of patients with neurological diseases that might not be caused by rotavirus infection. From these studies it was suspected that the raised anti-rotavirus antibody titre was due not only to invasion of rotavirus into central nervous system (our former case report ${ }^{1}$ ) but also due to impairment of blood brain barrier or non-specific intrathecal production (our 17 cases and the patients with multiple sclerosis reported by Vartdal et $a l^{5}$ ).

This work was supported by the Ministry of Education Grant-in Aid for Scientific Research, Japan.

\section{References \\ ${ }^{1}$ Ushijima $\mathrm{H}$, Bosu $\mathrm{K}$, Abe $\mathrm{T}$, et al. Suspected rotavirus encephalitis. Arch Dis Child 1986;61:692-4. \\ ${ }^{2}$ Shinozaki T, Araki K, Ushijima H, et al. Specific IgA antibody in nasal washes from patients with rotavirus infection. Pediatr Infect Dis 1985;4:299-300. \\ 3 Ohno A, Taniguchi K, Sugimoto K, et al. Rotavirus gastro- enteritis and afebrile infantile convulsion. No To Hattatsu 1982;14:520-1. \\ ${ }^{4}$ Salmi T, Arstila P, Koivikko A, et al. Central nervous system involvement in patients with rotavirus gastroenteritis. Scand $J$ Infect Dis 1978;10:29-30. \\ 5 Vartdal F, Vandvik B. Multiple sclerosis. J Neurol Sci 1982;54:99-107.}

Correspondence to Dr H Ushijima, Department of Pediatrics, Teikyo University School of Medicine, Kaga 2-11-1, Itabashi-ku, Tokyo 173, Japan.

Received 1 September 1986

\title{
Improving facilities for children in an accident department
}

\author{
P W RICHMOND, R C EVANS, AND J R SIBERT
}

Departments of Accident and Emergency Medicine and Child Health, Cardiff Royal Infirmary, Wales

SUMMARY A separate waiting and treatment area for children was established within an existing general accident and emergency department at relatively little cost. We describe how this was achieved and how it has benefited the children attending the department.

Figures for attendances by children at accident and emergency departments in the United Kingdom are incomplete, but it has been estimated that there are two million such attendances annually. ${ }^{1}$ In South Glamorgan we have shown that up to $20 \%$ of the population under the age of 15 attend the accident and emergency department in a year. ${ }^{2}$
It is generally recognised that children should be given priority with their assessment and should not be expected to wait and be treated in the proximity of ill, and occasionally violent and abusive, adults. The provision of separate waiting and treatment areas is a logical way of dealing with this problem and has been recommended for many years. ${ }^{3}$ The Court report, however, showed that only $11 \%$ of accident and emergency departments provided separate facilities for children. ${ }^{4}$ In a more recent survey by the British Paediatric Association standing committee on accidents in children only $25 \%$ of hospitals that replied to a questionnaire provided separate waiting and treatment areas. ${ }^{1}$

We describe how paediatric accident and emergency services were improved in an already 
existing general accident and emergency department at our hospital, with benefit to the patients and staff and with relatively little expenditure.

\section{Methods and results}

Our hospital is the only one with a major accident and emergency department in South Glamorgan, where the population in 1984 was 394400 , including 76800 children under the age of 14 . This population increases in the summer months with tourism. In 1985 there were 93000 attendances, of which 75000 were new. Mean daily attendances of children 14 years and under varied from 33 in January 1986 (range 19-49) to 61 in June 1986 (range 45-85). The department itself was originally converted from two 'Nightingale' wards built in 1883. One hundred years later, although priority was given to children, they were still managed alongside adult patients, sharing common waiting areas and treatment rooms.

In 1983 the consultants in the accident and emergency department, together with the liaison consultant paediatrician, decided to establish a separate paediatric unit within the department. There were initial reservations about this move from some senior nursing and clerical staff and there were also considerable financial constraints.

A rather spacious plaster room was used only in the late evenings and overnight, and a waiting area for this facility was in close proximity. The conversion involved separating this plaster room into two areas by a partition wall, and a much smaller area was retained as the plaster room. This left a small, but none the less adequate room, $9^{\prime} \times 14^{\prime}$, which already contained suction and oxygen points and a series of wall cupboards, all of which were retained. The area outside was converted into a combined waiting/play area. Toilet facilities were already available and were retained for use by the paediatric unit. Facilities for mothers to feed and change their babies were provided. The total cost of this conversion was under $£ 2000$, including provision of the partition wall, decoration, and labour (1983 costs).

Children arrive through a common entrance and reception area and are registered before being directed to the paediatric area. Only children under the age of 11 are managed in the unit because of the restriction of space. The recently converted room is used for assessment, for treatment, and also as a redressing clinic, and a dental suite opposite is readily available and used for some suturing. Facilities for the resuscitation of the very severely ill and injured child are shared with adult patients in a separate area where ensuite $x$ ray is available.

The paediatric unit is staffed between 0900 and $2100 \mathrm{~h}$ by a registered children's nurse together with nursing staff from the accident and emergency department. A senior house officer from the accident and emergency department rotates through the unit and paediatric junior and senior staff are available for consultation and visit the unit often. A consultant paediatrician has a liaison role and is involved in policy making within the unit.

The initial resistance of some staff has been replaced by enthusiasm. There have been clear benefits in the tolerance of children to examination and treatment and both parents and children find the unit more acceptable and less stressful. Separation of the children from the adults has also helped in the management of the adults.

\section{Discussion}

'The optimum care of children in hospital requires specially designed accomodation and professional staff trained to meet their needs and the needs of their parents. ${ }^{4}$

Despite this, many accident and emergency departments are housed in existing parts of old hospitals and accommodation is far from ideal. Indeed, even some new purpose built departments still lack separate paediatric treatment and waiting areas. Children should be shielded from adverse sights and sounds in an otherwise busy, distressing, and often frightening accident and emergency department. In a recent survey, out of 189 hospitals that replied, 66 did not even keep records of the number of children attending their departments and thus they can make no sensible attempt to estimate the demand children place on their services. In addition, only $15 \%$ provided a state registered children's nurse, although $47 \%$ had access to a liaison health visitor. There is obviously room for improvement. ${ }^{5}$

There are only two consultants in paediatric accident and emergency medicine in the UK (Liverpool and Sheffield) and most children attend a general accident and emergency department, under the supervision of an accident and emergency consultant, where children account for between a quarter and a third of total attendances.

The causes of attendance vary from trauma, acute illness, child abuse, and social disease to cot deaths, and staff should be adequately trained to deal with these matters and provided with adequate facilities in a warm, well lit area. Indeed, accidents are the principle cause of death between 1 and 15 years of age, and this has major implications for accident and emergency services.

Adaptations can be made to improve the delivery of a paediatric accident and emergency service within existing building and financial constraints. 
The establishment of the paediatric unit at our hospital has been a success, despite its limitations. The unit is used daily, including weekends, from 0900 to $2100 \mathrm{~h}$, when most children attend an accident and emergency department, but it remains impractical to staff overnight with existing restrictions on medical and nursing staff levels. Resuscitation areas are shared, but this would seem to be perfectly acceptable in view of the severity of the illness/accident, the small percentage of children requiring resuscitation, and the high cost of installing such specialised equipment. None the less, some paediatric resuscitation equipment is kept within the paediatric area.

Despite these limitations, however, separate waiting and treatment areas could be established in many existing accident and emergency departments with a little thought and planning and within existing financial constraints.

\begin{abstract}
References
1 The Standing committee on Accidents in Childhood of the British Paediatric Association and British Association of Paediatric Surgeons. Report on facilities for children in accident and emergency departments. London: British Paediatric Association, 1985.

2 Sibert JR, Maddocks GB, Brown BM. Childhood accidents - an endemic of epidemic proportions. Arch Dis Child 1981;56: 225-6.

3 Anonymous. Memorandum on the management of accidents in childhood [Editorial]. Br Med J 1967;iii:103-5.

4 Committee on Child Health Services. Fit for the future. (The Court report) London: HMSO, 1976.

5 Jackson RH. Children in accident and emergency departments. Br Med J 1985;291:991-2.
\end{abstract}

Correspondence to Dr J R Sibert, Department of Child Health, Llandough Hospital, Penarth, South Glamorgan CFG 1XX, Wales.

Received 7 October 1986

\title{
Herpes oesophagitis in a healthy 8 year old
}

\author{
H LAMBERT AND E J EASTHAM
}

Department of Child Health, Royal Victoria Infirmary, Newcastle upon Tyne

SUMmary An 8 year old, immunocompetent child developed a severe acute herpetic oesophagitis in the absence of oropharyngeal lesions. Intravenous treatment with the antiviral drug, acyclovir, relieved symptoms within 24 hours.

Herpes virus type 1 is a commonly reported cause of oesophagitis in autopsy studies and in immunocompromised or debilitated patients. It has also been reported in otherwise well young adults, causing a self limiting but often prolonged illness. ${ }^{1-4}$ The condition seems to be uncommon in healthy children, with only three case reports, all from America, aged under 16 years. ${ }^{56}$ We report an 8 year old boy in whom the diagnosis would not have been made without the use of upper gastrointestinal endoscopy.

\section{Case report}

The patient presented with a three day history of progressive retrosternal pain, made worse by swallowing and unrelieved by aluminium hydroxide. $\mathrm{He}$ had been unable to eat solids and had taken only small amounts of fluid. He denied any ingestion of corrosive agents and had previously enjoyed excellent health. His mother and 6 year old brother had a history of recurrent herpes labialis. On examination, he had mild cervical lymphadenopathy and a temperature of $37 \cdot 7^{\circ} \mathrm{C}$. No other abnormality was found, and, in particular, there were no skin or oropharyngeal lesions.

Initial investigations included a normal full blood count and barium swallow examination. The following morning, upper gastrointestinal endoscopy revealed severe inflammation of the whole length of the oesophagus, which was worse distally, with oedema, contact bleeding, and multiple small superficial ulcers (some in clusters, some linear, and some isolated). There was also a copious white, mucopurulent exudate. Biopsy specimens were taken for histopathological and virological examination, and later the same day herpes virus was identified by an electron microscopic immunofluorescence technique. This was subsequently confirmed as Herpesvirus hominis type 1 on culture. The virus was not identified from nasopharyngeal secretions. Histology confirmed the acute severe oesophagitis, although Cowdry type B inclusions were not seen.

The patient was begun on intravenous acyclovir 5 $\mathrm{mg} / \mathrm{kg}$ every eight hours, which was continued for five days. His response was dramatic; within 18 